\title{
A SUBJETIVIDADE DO PROFISSIONAL DA ODONTOLOGIA PÓS-REESTRUTURAÇÃO PRODUTIVA: ÉTICA E ESPECIALIZAÇÃO
}

\author{
THE SUBJECTIVITY OF THE DENTISTRY PROFESSIONAL AFTER PRODUCTIVE RESTRUCTURING: ETHICS \\ AND SPECIALIZATION
}

LA SUBJETIVIDAD DEL PROFESIONAL DE ODONTOLOGÍA POST-REESTRUCTURACIÓN PRODUCTIVA: ÉTICA Y ESPECIALIZACIÓN

\author{
Doris Gomes ${ }^{1}$ \\ Flávia Regina Souza Ramos ${ }^{2}$
}

Resumo Um novo tipo de relacionamento entre ciência, tecnologia e indústria na contemporaneidade estimula a forte expansão da realização do consumo de bens e serviços especializados, construindo diversificados problemas éticos nesse processo. Este artigo objetiva analisar a relação entre ética, especialização e mercado de trabalho na odontologia pós-reestruturação produtiva. Trata-se de pesquisa qualitativa exploratório-descritiva, com aplicação de um questionário em trinta alunos de um curso de especialização do sul do Brasil. As categorias foram construídas por meio dos problemas éticos apontados nos discursos dos profissionais e analisadas pelo método textual discursivo. As categorias estudadas foram a busca da especialização como imperativo para o diferencial de mercado e os problemas éticos na construção de novas necessidades de consumo estético e especializado com base em esquemas de convencimento singulares profissional-paciente. Um quadro de crise paradigmática da profissão odontológica estimula a ampliação das especialidades pautadas no consumo estético, o que amplifica a importância do debate da ética na formação lato sensu e, também, na formação permanente no trabalho em saúde bucal. Indica-se a necessidade de participação proativa dos conselhos profissionais, entidades de classe e instituições governamentais relacionadas à saúde bucal na construção do debate ético-bioético voltado ao trabalho e formação profissionais. Palavras-chave ética; mercado de trabalho; especialização; saúde bucal.
Abstract A new type of relationship that has developed between science, technology, and industry in modern life encourages a strong expansion in the consumption of specialized goods and services, building diverse ethical issues in this process. This article aims to analyze the relationship between ethics, specialization, and the labor market in the productive post-restructuring of dentistry. It is an exploratory-descriptive qualitative study involving the application of a questionnaire among thirty students of a specialization course in southern Brazil. The categories were constructed through the ethical issues highlighted in the discourse of professionals and analyzed using the discursive textual method. The categories studied were the pursuit of specialization as an imperative to stand out on the market and ethical issues in the construction of new needs for aesthetic and specialized consumption based on singular patient-patient convincing schemes. A picture of a paradigmatic crisis in the dental profession encourages the expansion of specialties guided by aesthetic consumption, which, in turn, amplifies the importance of the ethical debate in the lato sensu training and, also, in continuing education in work in oral health. There is a need for a proactive participation of professional councils, professional associations, and government institutions related to oral health in the construction of the ethical and bioethical debate focused on professional work and training.

Keywords ethics; labor market; specialization; oral health. 


\section{Introdução}

Nos anos dourados da economia keynesiana pós-Segunda Guerra Mundial um dos períodos de maior expansão da tecnologia, do consumo de massa e do capital (Hobsbawm, 2002) - a ideia de saúde como bem-estar é construída pela Organização Mundial de Saúde (OMS). O consenso keynesiano do welfare state procurava conciliar a 'anarquia' do mercado com o planejamento do Estado, mediante a adoção de políticas econômicas anticíclicas com elevação do padrão de consumo de bens e serviços de parcela significativa dos trabalhadores. O direito à saúde como conquista de cidadania foi incorporado na construção dos diversificados sistemas universais de saúde, especialmente em países desenvolvidos. Com base na ética utilitarista de felicidade e no sonho de consumo da 'medicina do bem-estar' (Gracia, 2010), esse processo impulsionou a complexificação das profissões no campo da saúde e a ampliação crescente de novas necessidades. A medicalização da vida assumiu um papel normalizador dos indivíduos e a ética passou a se pautar, também, pelo que é saudável, como sinônimo de bom.

Porém essa utopia do welfare state se esgotou já em fins da década de 1960, desembocando nos processos de reestruturação produtiva e financeirização do capital, onde dominam, agora, os grandes interesses do mercado financeiro em detrimento do investimento produtivo e do pleno emprego.

A reestruturação produtiva ou terceira revolução industrial surge pautada na automação e na inovação tecnológica, transformando a organização da produção. Há uma diminuição da classe operária industrial tradicional aliada à enorme ampliação do assalariamento no setor de serviços, boa parte dele precarizado (Pires, 2008).

A realização das potencialidades produtivas da sociedade é elevada a uma nova dimensão, sob um novo tipo de relacionamento entre ciência, tecnologia e indústria. O consumo de bens e serviços passa não mais à realização de necessidades, mas à sua própria produção. A ciência e a tecnologia acabam subordinadas à produtividade, obedecendo ao imperativo abstrato da 'realização' da lucratividade (Mészáros, 2002). O consumo estético é massificado como fetiche de felicidade aparente, uma ideologia necessária à dissimulação dos riscos sociais desse tipo de desenvolvimento.

A apropriação da subjetividade humana pela ampliação do trabalho imaterial (construtivo, criativo e em rede) nessa nova organização da produção exige um alto grau de habilidades ético-cognitivas do trabalhador para a tomada de decisões e escolhas, possibilitando um indivíduo mais reflexivo. Entretanto, as inovações sociometabólicas resultantes dessa reestruturação se traduzem numa tempestade ideológica de valores e utopias de mercado construtoras de um homo 
economicus atomizado e supervalorizado como competitivo e empreendedor ocultando-se o fato de que esse mer-cado não é para todos (Alves, 2011).

Um novo nexo de saber-fazer e saber-comunicar educa o indivíduo a atuar competitivamente num ambiente de precarização no trabalho, estimulando a busca do individual e privado sobre o coletivo/social, e subestimando o saber-ser. Para Milton Santos (2011), esse processo ganhou destaque mundial nas últimas décadas. A concorrência atual não é mais a velha concorrência, pois a competitividade toma o lugar da competição, sobretudo, eliminando qualquer forma de compaixão. Procura-se, agora, vencer o outro a todo custo, esmagando-o, para tomar o seu lugar.

As necessidades em saúde que já haviam adquirido conotação de bens de consumo sem limite de mercado na 'era dourada' começam agora a fazer parte de uma abordagem lucrativa com potencial ainda superior de acumulação de capital, precarização do trabalho e biopoder (Žižek, 201 la; Pelbart, 2003). A construção desse novo ethos social se transforma em um grave problema nas sociedades contemporâneas quando a ética acaba subsumida aos interesses de mercado. Essa nova relação indivíduo/coletivo sugere que, quando não há resgate dos diferentes sentidos e múltiplos significados do trabalho para mobilização de vontades na construção de projetos coletivos, prevalecem os processos ainda hegemônicos de banalização do individualismo narcísico e hedonista, e do conformismo.

Entretanto, o trabalho percebido como espaço mobilizador da subjetividade contém um debate de valores com potencial de transformação do sujeito trabalhador e das relações sociais. Segundo Dejours, Abdoucheli e Jayet (2007), as motivações subjetivas da dominação e do consentimento-adesão, com suas implicações éticas, passam por um processo de sofrimento e banalização que implica responsabilidades. Um processo que pode ser interrompido, controlado ou dominado por decisões humanas que dependem da vontade, da liberdade e do poder de controle sobre elas, portanto decisões que podem ser potencializadas pelo conhecimento do real funcionamento de todo esse processo (Dejours, 1992).

A odontologia no mundo contemporâneo, sua transição epistemológica (Gomes e Da Ros, 2008) e profissional, não está fora da construção dessas novas subjetividades que atendem às necessidades da modernidade capitalista, pois cada sociedade produz seus modos de subjetivação. Desse ponto de vista, a análise dos já clássicos, mas também dos novos problemas éticos advindos das mudanças nos processos de trabalho pós-reestruturação produtiva, merece uma reflexão crítica. A construção de nova intersubjetividade na saúde parece exigir um debate bioético que relacione questões como novas tecnologias, ideologia e mercado de trabalho. 
A democratização do acesso e da prevenção/promoção como parte de um mercado para além da odontologia clínica, em direção a uma lucrativa indústria do bem-estar, acaba ampliando o mercado clínico especializado. Diferentemente de outras profissões na área da saúde, a odontologia construiu seu referencial profissional baseado quase exclusivamente na lógica liberal - que classicamente rivaliza o bom serviço com o desejo de lucro. Entretanto, quando essa tradição liberal não consegue mais sustentar a realização do status profissional, é atravessada por uma alteração substancial na relação profissional-paciente: antes baseada em uma moral deontológica do serviço e no consumo da cura aliado à estética, hoje potencializada na ideia do consumo/lucro/produtividade.

Uma relativa fragmentação desumanizada nos cuidados à saúde bucal surge como subproduto da competitividade-produtividade do mercado de trabalho, o que interfere diretamente na tomada de decisões e na construção da subjetividade profissional. A crise paradigmática da profissão traz um sentido de transformação nas relações de trabalho na odontologia e abre espaço para um debate em torno da humanização e da ética. As distintas soluções no mix público/privado apontam para a contestação da lógica liberal: no serviço privado, há ênfase no consumo estético por meio das especializações e produção empresarial ou de grupo; no público, pauta-se uma nova excelência para a odontologia coletiva.

Para discutir esse cenário contemporâneo, foi realizado o presente estudo, que tem como principal objetivo a análise dos problemas éticos nas experiências de profissionais 'em especialização' que atuam no mercado de trabalho da odontologia no contexto brasileiro pós-reestruturação da produção. Procurou-se compreender a conexão entre ética, especialização e mercado de trabalho, debatendo-se as questões éticas à luz das novas relações de trabalho identificadas.

\section{Trajeto metodológico}

A pesquisa é qualitativa do tipo exploratório descritivo 3 e foi realizada por meio de um questionário aplicado em sala de aula com a participação voluntária de trinta odontólogos dos cursos de especialização em ortodontia e implantodontia de uma instituição de ensino superior do sul do Brasil. A amostra privilegiou os sujeitos sociais que detêm as características necessárias ao conhecimento buscado, por possuírem vínculos de trabalho privados diferenciados - consultórios, clínicas ou empresas privadas -, e alguns, também, no serviço público. O acesso por via institucional se deu mediante autorização dos cursos de especialização referidos e, após essa autorização, foram feitos contatos prévios e convites aos profissionais. Para garantir o 
anonimato, os sujeitos são identificados pela sigla CD (cirurgião-dentista), acompanhada de numeração crescente.

As três perguntas do questionário relacionam-se às mudanças no mercado de trabalho na odontologia, à escolha da especialização para atuação nesse mercado e aos problemas éticos encontrados na atuação profissional na contemporaneidade. Os resultados foram analisados pelo método de análise textual discursivo (Moraes e Galiazzi, 2011), que organiza os argumentos em torno de: 1) desmontagem dos textos, na qual se faz um exame detalhado dos textos, seguido de sua fragmentação em unidades constituintes ou unidades-base (corpus/dados); 2) estabelecimento de relações, em que se constroem relações entre as unidades-base, formando-se sistemas de categorias; 3) captando o novo emergente, quando se busca uma compreensão renovada do todo mediante a nova combinação de sentidos expressados em um metatexto; e 4) processo de auto-organização, no qual novas compreensões emergem de um ciclo de análise do metatexto, gerando os resultados.

A execução do projeto passou pela solicitação ao Comitê de Ética em Pesquisa com Seres Humanos da Universidade Federal de Santa Catarina (CEPSH/UFSC/2461). Após a aprovação do projeto, foi dado início às atividades de entrevista. Os profissionais entrevistados foram orientados de forma clara e objetiva sobre o propósito e objetivos da pesquisa. O esclarecimento sobre aspectos do estudo e a obtenção de sua anuência foi feito através de um termo de consentimento livre e esclarecido. A participação ocorreu de forma voluntária, sem remuneração, com observação das condições de pleno exercício da autonomia, liberdade individual e anonimato propostas na resolução n. 196/96, do Conselho Nacional de Saúde, que regulamenta as diretrizes e normas de pesquisa com seres humanos.

\section{A busca da especialização como imperativo para o diferencial de mercado}

Com a mudança na distribuição de renda e ascensão das classes C e D, surgiram as clínicas ditas populares, muitas delas de não dentistas, vendo na odontologia um mercado promissor, já que existia população com demanda reprimida, capital e mão de obra abundante (portanto, barata). Iniciou-se, assim, uma guerra de preços na qual os autônomos quebraram ou mudaram para o caminho da especialização (CD 15).

Resolvi fazer um curso de especialização para aperfeiçoar meu conhecimento e ter um diferencial no mercado de trabalho (CD 3).

A adesão dos profissionais a um novo quadro de trabalho especializado parece estar associada à necessidade de diferenciação no mercado de trabalho, 
e visa tanto à melhoria da qualidade no atendimento quanto ao aumento da lucratividade. No planejamento pessoal e empresarial, essa diferenciação amplia as possibilidades de atendimento e clientela, um imperativo da competição e da concorrência que surge como resultado da saturação do mercado de trabalho na odontologia, o qual absorve cotidianamente grande quantidade de novos profissionais.

Para Nunes, Leles e Gonçalves (2010), a escassez de oportunidades e a tentativa dos profissionais de garantir o sucesso, melhorar a renda e obter prestígio social levam ao caminho da especialização. Um aperfeiçoamento profissional é preponderante na abertura de novos caminhos e alternativas de trabalho. E é uma necessidade social, profissionalmente construída e mercadologicamente estimulada.

Depois de dois anos trabalhando em consultório, senti a necessidade de fazer um curso de especialização devido à procura dos pacientes por esse tipo de tratamento - na clínica não havia ainda essa especialidade - e, também, pelo meu gosto na área (CD 12).

Devido à necessidade de profissionais nessa área em minha região (CD 4).

[Para] Aumentar as possibilidades de tratamento para o paciente e melhorar a rentabilidade (CD 13).

O momento da escolha pela especialização e pela área de atuação é definido por diferentes necessidades percebidas pelos profissionais: necessidades sociais regionalizadas, da clínica ou apresentadas pela clientela, observadas nos próprios locais de trabalho; e necessidades ou desejos pessoais/profissionais no sentido do aprimoramento técnico para a melhoria da qualidade, por uma preferência pessoal pela área de atuação especializada ou, até mesmo, por um sentido de aptidão.

\section{Um ideal historicamente construído de excelência profissional}

Acho fundamental o constante aperfeiçoamento profissional, independentemente de ser uma atualização, um aperfeiçoamento ou uma especialização... O mercado de trabalho está mais competitivo, a cada dia novos cirurgiões-dentistas entram no mercado e é importante que estejamos preparados para tal concorrência (CD 11).

Devido ao meu crescimento profissional e social, me senti na obrigação para com meus pacientes e para comigo de oferecer o melhor, sempre (CD 7). 
Uma coerção intersubjetiva é construída desde antes da formação profissional por um modelo biomédico socialmente vivenciado e, posteriormente, por um ensino formal já especializado e voltado para um mercado de trabalho liberal-privatista. O advento da revolução científica nos séculos XIX e XX permitiu grandes avanços e complexificações teórico-práticas no campo das ciências médicas, levando a uma maior divisão social do trabalho - um processo que acaba se impondo à odontologia e que caracteriza a especialização como traço essencial dessa nova ordem racionalizadora. A especialização na forma de disciplinas separadas foi o mecanismo estratégico adotado pelas profissões para manter sob controle os avanços e os novos conhecimentos - permite um aprofundamento do conhecimento específico e assegura o monopólio do saber e da prática (Machado, 1997).

A especialização ou a superespecialização, ao mesmo tempo em que preserva a autonomia no serviço, fragmenta o conhecimento e parcela o ser humano, dificultando a consciência de uma dimensão do indivíduo enquanto sujeito ativo de relações afetivas, com determinadas experiências de vida e parte de um todo social (Pires, 2008). Ela aparece como reflexo 'bem-sucedido' de uma identidade profissional construída sob a hegemonia do serviço privado e do ideal liberal: como valorização e satisfação no trabalho. Essa identidade é parte da ontogênese da profissão: resultado de constante procura por uma excelência no serviço odontológico no sentido de um saber-fazer técnico, que tem na essência da sua organização a transformação dos cuidados em saúde bucal em bens de consumo - voltados na atualidade para a produtividade e a competitividade no mercado.

Acredito que o mercado de trabalho atualmente está muito desvalorizado, isso é uma pena, temos que buscar sempre aperfeiçoamento para podermos ingressar no mercado com satisfação (CD 1).

O percurso da formação profissional age como construtor de uma subjetividade forjada no imaginário coletivo e ancorada no ensino da saúde bucal, numa concepção que tem "a doença como referência e o curativo biologicista como paradigma” (Ceccim et al., 2009, p. 207). Além de um saber-fazer tecnicista e/ou especializado, do poder autônomo e hermético do consultório - em torno de si mesmo - e com status de classe, tem "sua concepção de prática centrada na assistência odontológica ao indivíduo doente, e realizada com exclusividade por um sujeito individual no restrito ambiente clínico-cirúrgico" (Narvai, 2006, p. 143).

Um modelo já incorporado a partir de uma formação baseada nas disciplinas/especialidades desde a criação dos cursos de odontologia no Brasil (decreto imperial n. 9.311 de 1884), aprofundado na década de 1960 pelo modelo de ensino flexneriano, que compartimenta o conhecimento científico 
em disciplinas separadas e direcionadas à relação meramente clínico-individual, desconsiderando a complexidade das relações humanas e suas conexões sociais. Um modelo que, mais recentemente, se ancorou na ideologia de mercado hegemônica no período neoliberal, que amplia substancialmente as necessidades estéticas, entre outras, consoante aos aspectos subjetivos da sociedade moderna, na qual o consumo da medicina/odontologia especializada se transforma numa necessidade socialmente construída. Assim, a ideia de sucesso profissional estaria relacionada à dedicação a uma ou mais especialidades, percebida como uma qualificação indispensável e definidora do perfil profissional em sua adequação ao mercado de trabalho contemporâneo.

Num sentido contrário à saúde bucal apenas como um elaborado produto de consumo estético e artesanal/tecnológico, há todo um investimento do Estado brasileiro na reforma do ensino pautada nas necessidades sociais. A odontologia passa a ser percebida como prática social e o indivíduo, como sujeito do próprio processo saúde/doença. A construção de novos currículos nos cursos de odontologia segue os preceitos da Lei de Diretrizes e Bases da Educação (LDB) e das Diretrizes Curriculares Nacionais (DCNs), que apontam para uma formação profissional generalista, humanista, crítica e reflexiva.

A busca do conhecimento interdisciplinar, tanto prático quanto teórico, não pautado nas especializações já na graduação é marca desse processo de transformação da educação superior na área da saúde bucal. Assim, a formação de um profissional com ampla capacidade técnica e humana deve servir à transformação da realidade em benefício da população (Oliveira, Melani e Silva, 2011), um profissional que atue com rigor técnico e científico, “capacitado ao exercício de atividades referentes à saúde bucal da população, pautado em princípios éticos, legais e na compreensão da realidade social, cultural e econômica do seu meio" (Brasil, 2002).

Entretanto, a tendência à persistência do tradicional sistema de ideias e práticas, ancorado no estilo de pensamento da ciência odontológica multicausal-biologicista, parece contrariar esse potencial de mudança. Finkler, Caetano e Ramos (2011) constatam a pouca valorização da formação humanística, cultural e política em relação à orientação didática no processo educativo na graduação, em cenários de ensino-aprendizagem que partem, ainda, de pressupostos e métodos bastante tradicionais. Para Araújo e Medeiros (2010) parece necessário transpor limites históricos, reestruturar a formação dos recursos humanos e renovar as relações interpessoais entre os profissionais da saúde.

Dentro dessa transição educacional e de incorporação da pauta de humanização em saúde bucal, duas questões distintas e, ao mesmo tempo, interligadas podem ser destacadas: hegemonia do ensino privado nos cursos de pós-graduação lato sensu; e separação ainda persistente entre técnica e humanização. 
Mesmo ligados, obrigatoriamente, aos estabelecimentos de ensino superior como preconiza o Ministério da Educação e o Conselho Federal de Odontologia (CFO), a ampla maioria dos cursos de especialização ou lato sensu nos diferentes campos da odontologia requer um desembolso financeiro por parte dos profissionais, onerando-os substancialmente. As poucas especializações público-gratuitas estão voltadas, normalmente, aos trabalhadores da Estratégia Saúde da Família (ESF) - modelo assistencial da atenção básica implantado no Brasil em fins da década de 1990 e fundamentado no trabalho de equipes multiprofissionais que desenvolvem ações a partir do conhecimento da realidade das comunidades onde estão inseridas e das necessidades dessa população.

Somada à necessidade de um aperfeiçoamento continuado e especializado no campo das diferentes 'técnicas', essa realidade de pagamento constitui sério risco de mercantilização da educação especializada, com tendência a uma formação pouco crítica e reflexiva, e socialmente descomprometida. Assim, a necessidade do debate e do ensino da ética/bioética nos cursos de especialização fica ainda mais amplificada. E não somente do ponto de vista das pesquisas com seres humanos, sujeitas aos comitês de ética em pesquisa e voltadas às monografias com potencial de publicação que fazem parte do rol das pesquisas em saúde humana - hoje, cerca de $25 \%$ de toda a atividade de pesquisa no país (Guimarães, 2011) -, mas, além disso, da pauta de uma responsabilização/comprometimento com o outro no cuidado especializado, no sentido de uma clínica voltada para a relação profissional/paciente/sistema de saúde/sociedade.

\section{Um sentimento hegemônico de desvalorização da profissão}

Há uma valorização maior por parte dos pacientes da sua saúde bucal. Há também mais acesso, conhecimento (CD 10).

Alguns discursos relacionam a maior valorização social da saúde bucal à adesão de um número maior de pacientes à odontologia, num 'mercado consumidor' mais exigente. Entretanto, é construído um sentimento de desvalorização profissional gerado pela crise de realização na oferta de serviços odontológicos, por uma acentuada concorrência interprofissional e pelo processo de precarização nas relações de trabalho.

Atualmente, infelizmente, acho que a odontologia perdeu o seu valor, por falta de união da classe. A prostituição da profissão é enorme e acho que nós profissionais não somos valorizados por nosso serviço (CD 6). 
Há a desvalorização do profissional quando [ele] se submete a trabalhar com valores muito abaixo da tabela, não cobra consulta (CD 3).

Os convênios odontológicos estão acabando com a profissão, e as clínicas populares funcionam como 'prostíbulo de dentistas'; eles aproveitam da necessidade de outros (CD 13).

A concorrência faz com que se multipliquem clínicas populares, onde muitas vezes o paciente é tratado como mercadoria e atendido de qualquer jeito (CD 10).

Essa significativa desvalorização profissional, associada à percepção de problemas éticos revelados nas expressões "prostituir-se", "roubar pacientes", "falar mal de colega" e "venda de si próprio", é vista como reflexo de relações concorrenciais num novo formato de organização da produção na odontologia, em especial convênios, planos de saúde e clínicas 'populares'. É estabelecida uma relação valorativa entre qualidade do atendimento, preços praticados e direitos trabalhistas; baixa remuneração dos planos de saúde; falta de valorização profissional e união da classe; alta concorrência; paciente tratado como mercadoria; e sistemas preestabelecidos de atendimento que atingem o tempo e a forma de sua condução.

Um dos maiores problemas que se encontra hoje em dia é a desvalorização do tratamento: muitos profissionais não cobram um preço ideal (geralmente [cobram] abaixo) para conseguir mais pacientes e isso, consequentemente, diminui a qualidade no trabalho. E a culpa é do próprio profissional que se sujeita a isso (CD 5).

O sonho do ideal profissional liberal bem-sucedido e satisfeito permanece vivo como imagem saudosista, uma utopia coletivamente construída e associada, hoje, aos conhecimentos especializados. O fracasso num mercado de trabalho altamente competitivo e sem perspectiva positiva de transformação, e sua correlação com inúmeros problemas éticos, é percebido como pessoal. A ideia construída intersubjetivamente de que o profissional está 'à sua própria sorte' no mercado de trabalho culpabiliza-o quando ele não consegue alcançar o status solicitado. Como categoria de trabalhadores, essa ideia transfigura o sentido de coletividade ao não relacionar os problemas profissionais contemporâneos às novas realidades de trabalho precarizado. Além disso, coloca em xeque o próprio objetivo do código de ética profissional, quando revela sua insuficiência e relativa ineficácia.

Há colegas que se acham melhores que outros, roubam pacientes ou 'transferem' pacientes de uma clínica para outra (CD 13). 
A saúde bucal coletiva nos moldes do serviço público ainda não é percebida como uma alternativa para o sucesso profissional; ao contrário, é relacionada a uma fuga da busca pela excelência. Conseguir galgar espaços profissionais e 'ganhar' a concorrência interpares é sinônimo de satisfação e sucesso. Desistir desse referencial de sucesso liberal-privatista, assumindo um comprometimento com o serviço público, significa fracassar profissionalmente.

Aumentou a competitividade, vejo que no meu trajeto profissional tenho crescido a cada ano. Mas, em contrapartida, tenho colegas que optam por menores responsabilidades, tanto financeiras quanto profissionais (empregos públicos) (CD 7).

A realidade de uma formação especializada e permanente em direção à construção de uma excelência técnico-estético-funcional e humana - especialmente voltada àqueles profissionais engajados no serviço público -, ainda é considerada não satisfatória.

\section{Mudança na organização do trabalho a partir da especialização}

O serviço está mais especializado. Trabalha-se muito de forma integrada com outros especialistas (CD 8).

Uma nova convivência interpares constrói novas intersubjetividades profissionais que se dão em diferentes formatos de relações de trabalho: interpares especialistas, precarizado-subcontratado, ou em equipe de saúde bucal. A luta pela sobrevivência e para manter-se no topo do mercado suscita a substituição do tradicional modelo clínico-geral centrado em consultório. Uma iniciativa mais profissionalizada, empresarial ou de grupo é a marca da reestruturação produtiva em saúde bucal. Nesse sentido, a especialização é percebida como uma técnica/tecnologia inevitável e via inquestionável para essa nova forma de organização da produção, desenvolvida com base no trabalho integrado interespecialista.

É construído um ambiente de trabalho mais coletivizado e propício às trocas interprofissionais, pautado num viés empresarial/comercial voltado para a concorrência e o aumento da produtividade. Essa realidade conforma um novo espaço de mediação ética com abertura para as novas tecnologias relacionais interpares, reguladas tanto pelo interesse financeiro em comum quanto pela convivência cotidiana não somente concorrencial. Ainda assim, mesmo esse modelo de gestão mais compartilhada está restrito aos interesses da empresa ou do grupo, o que pode significar adesão a uma ética relativizada, pautada em interesses particulares. 
As clínicas estão sendo administradas muito mais por profissionais que não são da área, por exemplo, administradores, que acabam por desvalorizar o profissional. Outro grande problema são os convênios (CD 24).

O trabalho precarizado em um ambiente clínico ou coletivo assume um sentido de proletarização da profissão sob diferentes modelos: assalariamento em clínicas 'populares'; subsunção aos interesses comerciais dos planos de saúde; remuneração por porcentagem ou por produtividade; e trabalho sem direitos legais assegurados, entre outros. Ainda com pouca regulação social e estatal efetiva, esses modelos organizativos da produção em saúde bucal conformam realidades de trabalho não percebidas como coletivas e assalariadas. As relações de trabalho, além de precárias, ainda se encontram subsumidas aos preceitos liberais, e o engajamento em lutas coletivas por direitos trabalhistas é pouco vislumbrado. Essa é uma realidade que deve ser melhor compreendida no atual estágio de transição da profissão odontológica.

Há um grande problema ético no nosso meio que é a falta de cumplicidade entre os colegas: sempre estão tentando derrubar uns aos outros (CD 18).

Na saúde bucal coletiva, a necessidade de incorporação das especializações acontece como uma ação afirmativa no sentido de democratizar e permitir maior acesso das populações a essas técnicas/tecnologias. Essa incorporação ocorre com base numa intencionalidade diferenciada de preceitos mercadológicos, que repercute, também, no trabalho em equipe. Como contraponto à lógica liberal e de mercado no Brasil, há, nas últimas décadas, ampliação substancial do serviço público/estatal por meio da ESF. O número de equipes de saúde bucal (ESBs) já chega a 19.500, e elas estão presentes em $85,3 \%$ dos municípios brasileiros. A especialização aparece como frente estratégica mediante a implantação dos centros de especialidades odontológicas (CEOs) e laboratórios regionais de prótese dentária (LRPDs) já em 2004, atingindo o patamar de 958 CEOs distribuídos por todo o território nacional (Narvai, 2013). Esse serviço é oferecido como continuidade à atenção básica e cobre, no mínimo, serviços de diagnóstico bucal (ênfase no diagnóstico do câncer de boca), periodontia especializada, cirurgia oral menor dos tecidos moles e duros, endodontia e atendimento a portadores de necessidades especiais (Brasil, 2002).

Para Narvai (2013), a prática de uma boa odontologia deve compatibilizar a atuação técnica do especialista com a luta pela melhoria da vida social. É uma postura que assume caráter político e, concomitantemente, de uma melhor condição para a prática odontológica, na qual cada profissional deve transformar-se num sujeito realmente participante de processos coletivos. Essa realidade parece abrir a possibilidade de superação de problemas 
éticos interpares e de humanização, crônicos da profissão, sob nova identidade profissional, muito além do velho ideal liberal isolado no consultório.

Entretanto, ao mesmo tempo em que se evidencia a necessidade de uma ética no trabalho conjunto interpares, a própria realidade concorrencial para a sobrevivência no mercado desencadeia conflitos éticos significativos. Inúmeros e crescentes processos são movidos cotidianamente nos Procons e conselhos da categoria relativos a regulamentações voltadas para a pós-graduação. A consolidação das normas para procedimentos nos conselhos de odontologia, aprovada pela resolução CFO n. 63/2005, sugere obrigatoriedade do debate ético/bioético nos cursos lato sensu, quando estipula uma carga horária mínima às disciplinas de bioética e ética e legislação (Conselho Federal de Odontologia, 2005). Além disso, uma nova configuração do Código de Ética Odontológico ao final de 2012 foi impulsionada por uma realidade de trabalho que subsume o conceito de saúde, boa parte das vezes, ao sentido estético do saber-fazer e que sobrepõe, em muitos casos, as necessidades de mercado/consumo à ética.

\title{
Problemas éticos na construção de novas necessidades de consumo estético e especializado
}

\begin{abstract}
Com o crescimento das especialidades, muitos dentistas tentam impor aos seus pacientes tratamentos relacionados à sua especialidade. Por exemplo, paciente com um sorriso relativamente agradável, mas com um pré-molar girovertido, não necessariamente precisaria usar aparelho ortodôntico; no entanto, muitos ortodontistas convencem o paciente a usar (CD 12).
\end{abstract}

É revelada pelos profissionais uma preocupação com esquemas singulares de convencimento na relação profissional-paciente, em especial quando são construídas necessidades de consumo estético/especializado pelo profissional. Os padrões sociais de beleza convencionados pela sociedade de consumo moderna podem adquirir status, também, de padrões científico/estético-funcionais de saúde bucal. Há espaços de conflito ético entre a autonomia do cidadão baseados em conceitos singulares de saúde, padrões de saúde/beleza mercadologicamente construídos, necessidade de ascensão/sobrevivência do profissional no mercado de trabalho odontológico e um saber-fazer especializado não subsumido ao 'dever ser' ético.

O profissional liberal clássico até o século passado era moralmente respeitado pela afirmação do serviço como de saúde, mantendo sob preceitos deontológicos o viés lucrativo. Pós-reestruturação produtiva, a saúde se transformou em bem de produção, com forte potencial de acumulação de capital. Aprofundou-se o viés comercial dos serviços de odontologia: o 
saber/fazer-poder hegemônico é pautado não mais na cura, mas no consumo estético e especializado que se realiza no mercado. A quebra da tradicional ética deontológica paternalista, ao mesmo tempo em que jogou por terra a impunidade jurídica e a imunidade social do profissional da saúde (Gracia, 2010), instigou um olhar vitimado e conspirativo do profissional em um novo quadro de relações profissional-paciente. O modelo clássico do compromisso ético paternal que sempre blindou os privilégios profissionais é substituído pela autonomia individual ou pelo direito cidadão à saúde, o que coloca em xeque o modo clássico de gestão do saber/poder profissional, já incipiente diante de novos problemas.

No momento histórico em que a saúde torna-se fonte importante de despesas (no período pós-1940/1950), são aperfeiçoados diversos aparelhos de poder para se encarregar dos 'corpos', no sentido de ajudá-los, e, se necessário, coagi-los, a garantir sua saúde. A ciência médica é desbloqueada técnica e epistemologicamente por um novo arranjo, altamente social, de organização da saúde. Antes, a noção de nocividade da medicina era proporcional à sua não cientificidade; agora é o contrário: a própria medicina se torna perigosa precisamente pelo seu saber/ciência. Os reflexos sociais dos riscos dessa cientificidade colocam a questão da vida para além do indivíduo, e diversificadas questões, como trabalho e política social, passam a estar ligadas à área da saúde. Uma nova forma de controle e disciplinamento social traz à tona a problemática de governar. As técnicas de governo ou governamentalidade se tornam questão central e espaço real da luta política, como forma de manutenção do Estado capitalista (Foucault, 2000).

Segundo Žižek (2011a), a hegemonia do discurso científico torna inócua toda uma rede de tradição simbólica como sustentáculo da identidade/identificação do sujeito "em termos políticos, a mudança é do Poder fundamentado na autoridade simbólica tradicional para a biopolítica" (Žižek, 201 la, p.51). O espaço de autorreflexividade concorre cotidianamente com padronizações subjetivas de um autocontrole individual e normalizado, como biocontrole social complexo. Para Pelbart (2003), essa biopolítica estaria na contemporaneidade situada numa estratégia mais ampla de biopoder: trata-se, agora, de garantir a sobrevivência de uma população dentro de uma lógica biológica, o que desloca o interesse do poder do corpo (poder disciplinar) para a vida.

Os profissionais da saúde bucal passam a conviver com esse poder associado ao disciplinamento/normalização sobre os corpos/indivíduos/vida, uma construção embasada na ciência e na técnica que é, ao mesmo tempo agora, subsumida ao imperativo do consumo/lucratividade/controle. Os interesses científico-sociais e o desenvolvimento tecnológico são coagidos pelos interesses de mercado, e a especialização ou ultraespecialização passa a ampliar ainda mais as necessidades/desejos e riscos. 
Para Giddens (1997), o trabalho especializado hoje serve como apoio a todos os generalismos, mas os próprios especialistas transformam-se em público leigo quando confrontados com diversificados sistemas abstratos e com diferentes campos de especialidade que afetam as suas vidas. Como consequência dos diversos movimentos contraditórios dessa especialização e da imprevisibilidade das ameaças do desenvolvimento técnico-industrial, uma autorreflexividade é produzida. O indivíduo é chamado a refletir e decidir cotidianamente, mas acompanhado pela incerteza do risco embutido e pela coerção heterônoma do consumo.

Relações singulares com orientação universalizante adquirem forma de uma individualização em contexto de forte coerção social. Essa individualização acontece sob condições de um processo de socialização que progressivamente impossibilita emancipações individuais: ao se desonerar das estruturas e vínculos tradicionais, o indivíduo recebe em troca as pressões do mercado de trabalho e de uma subsistência baseada no consumo, e nas padronizações e controles contidos em ambos (Beck, 2010). Redes de solidariedade antes consideradas basais das relações sociais são trespassadas por sentimentos de insegurança e desconfiança que se traduzem em sofrimento ou cinismo. Ao mesmo tempo em que o desejo de segurança constrói a necessidade de identidade, há uma fuga do tradicional como algo ultrapassado (Bauman, 2005).

Parte dos profissionais da saúde torna-se incapaz de se solidarizar com o outro - desconhecido -, ou mesmo, de se comprometer com uma causa no sentido do outro - social -, o que configura importantes problemas éticos. O paradigma clássico tradicional de um dever moral paternalista do profissional é substituído por uma desconfiança reflexiva. Uma desconfiança associada a um risco e a um imperativo de consumo sempre iminentes que, por sua vez, podem se transformar facilmente em uma ética relativizada ou hedonista.

Ilusão com valores em clínicas populares, por exemplo, os valores são baixos, mas o tratamento não é finalizado ou é mal finalizado (CD 3).

Preços muito baixos, tratamentos sendo muito mal executados (CD 14).

Segundo Tsakos e Sheiham (2013), a avaliação de saúde por leigos difere daquela feita por profissionais, pois mantém relação com a funcionalidade, a qualidade de vida e o custo-benefício. Assim, na relação dialógica profissional-paciente, os fatores subjetivos psicossociais e culturais ligados aos conceitos de saúde e bem-estar devem ser considerados. Para Caprara, Lins e Franco (2011), essa relação deve se dar sob o signo da parceria, para que as diferenças de poder ou de compreensão da realidade não impossibilitem 
uma construção ética de adesão. Como parceiros dessa relação, é preciso que os membros de uma díade se comuniquem, se reconheçam e se compreendam.

Na relação intersubjetiva dialógica de busca pelo consenso, a realidade disforme tem que ser substituída por situações ideais de diálogo, ou seja, a disposição para um diálogo construtivo tem que ser eticamente comprometida. Caso contrário, a possibilidade de manipulação ou alienação dos participantes para que interesses particulares sejam acatados como universais, pode se configurar (Cortina, 2009). Numa construção humana moderna embebida de percepções hedonistas e egocentradas no indivíduo, oferecidas para o consumo e constrangidas pelo mercado, uma ética relativizada ou hedonista pesa sobre a disposição na busca pela verdade, em um dos lados do diálogo.

Como as necessidades individuais ou coletivas estão imbricadas com julgamentos de valores, o medo e a desconfiança não se relacionam apenas com o uso da tecnologia material e suas possíveis consequências e riscos, mas com esquemas relacionais pautados no conhecimento. Além disso, a adesão atomizada a uma ideologia de consumo como 'status de modernidade' coloca em jogo o comprometimento ético do profissional - na relação com a autonomia do paciente e os interesses da coletividade. Novos espaços de trabalho imaterial na saúde (produção de afetos, relações, comunicação, cooperação e envolvimento com comunidades) significam novos domínios para o próprio mercado: uma produção intelectual que antes estava excluída é, agora, mercantilizada (Žižek, 2011b).

Pode-se notar a grande busca pela estética. Muitos querem dentes mais brancos como aquele 'ator de novela', dentes mais 'retos' sem estar 'tortos'. Tem pessoas que mesmo que tenham dentes de parte posterior para restaurar, preferem os da frente (CD 2).

Num quadro em que há a interposição tecnológica entre o profissional e o paciente, o ato da consulta acaba se transformando em um espaço definidor do que deverá ser 'consumido' pelo paciente (Werneck e Ferreira, 2013). A coerção dos padrões estéticos de consumo pode sugerir uma falsa autonomia ao paciente/usuário, quando induzem necessidades-desejos construídos de forma heterônoma por interesses mercadológicos, assumidos como necessidade real pelo paciente e sustentados por profissionais para maximização dos lucros. Isso constitui um ethos de consumo que pauta novas necessidades/desejos em saúde bucal, absorvido pelos profissionais no mercado de trabalho odontológico especializado como coerção social. O que aparece ao profissional especialista como um conflito cotidiano entre produtividade, concorrência e imperativo da lucratividade, por um lado, e construção de um comprometimento ético numa relação dialógica pautada no 'ser' e no 'dever ser', por outro lado. 
A especialização tornou-se extremamente necessária para o profissional ser valorizado e para poder oferecer um trabalho com muita qualidade, o que é exigido pelos pacientes atualmente. Eles não procuram mais somente resolver a dor e desconforto dos dentes, mas procuram a estética idealizada (CD 17).

Já que nos dias atuais os implantes são um tratamento bem difundido e conhecido pelos pacientes, os mesmos nos questionam sobre tratamentos mais avançados (CD 9).

Ao mesmo tempo em que é socialmente exigida uma nova postura ética de respeito ao espaço de decisão autônoma do paciente, há um forte componente social/coletivo, como parte viva do mundo da comunicação e informação contemporâneo, que funciona como exigência normalizadora das vidas. Novas necessidades pautadas em diversificados signos de desejos passam a atuar sobre o trabalho profissional, não necessariamente com uma real autonomia do sujeito, necessidades que podem ser construídas sobre informações confiáveis adquiridas no campo especializado ou na literatura científica: artigos, reportagens etc., mas que, outras vezes, podem significar (des) informações padronizadas/normalizadas pela mídia televisiva ou falada, internet, trocas relacionais e místicas de toda espécie ou na ênfase do consumo pelo consumo como ideologia.

Quando a ética sucumbe a construções consumistas construídas pelo e para o mercado, o profissional adere de forma atomizada a uma 'exigência' de necessidade, por um consumidor previamente 'convencido', que nem sempre poderá ser considerada autônoma, mas que 'pode ser' comprada. Para Mészáros (2002), um novo tipo de relacionamento entre ciência, tecnologia e indústria eleva a realização das potencialidades produtivas da sociedade moderna a uma extensão anteriormente inimaginável, e a ciência e a tecnologia acabam subordinadas a essa produção. O consumo de bens e serviços passa a estar vinculado não mais à realização de necessidades, mas à sua própria produção, obedecendo ao imperativo abstrato da 'realização' ou lucratividade do capital.

Segundo Amorim e Souza (2010), os problemas éticos na prática odontológica ocorrem rotineiramente e podem envolver aspectos referentes ao paciente, à organização de saúde e ao relacionamento com os colegas e com a sociedade como um todo. O mercado e suas 'leis' seriam um dos grandes responsáveis pelo antagonismo entre prática técnica e prática social. Lacaz e Sato (2011) ressaltam que a separação entre a técnica e a tecnologia, de um lado, e o social, o cultural, o psicológico e o subjetivo, de outro, é uma falsa divisão que acontece nas práticas em saúde.

Para diminuir o fosso construído por essa divisão, uma abordagem ampliada e socialmente construída de ser humano que esteja além das 
fragmentações das ultraespecializações e das disputas fratricidas de mercado, pautada numa crítica social e num comprometimento com o outro, parece condição sine qua non como ideal ético para a odontologia. O debate da ética e da bioética na profissionalização lato sensu, bem como na pauta de uma formação permanente em saúde bucal, parece ser central para 'blindar' moralmente o profissional da odontologia, chamando-o a uma reflexividade sobre o próprio cotidiano do trabalho, como especialista e como cidadão, no sentido da edificação de uma bucalidade que transcenda interesses meramente mercadológicos.

\section{Conclusão}

A ideia ainda hegemônica de profissão liberal sofre forte influência da ideologia de mercado, trazendo novos problemas éticos ao campo da saúde bucal. São destacados quatro eixos de abordagem dos problemas éticos contemporâneos:

1) o trabalho em equipe interespecialista no sentido empresarial modifica as tradicionais relações interpares da odontologia liberal e deve ser melhor compreendido no atual estágio de transição da profissão;

2) o ideal liberal de sucesso profissional é ampliado pela ideia hegemônica do empreendedorismo e competitividade, num contexto destituído de um componente coletivo de luta, construindo uma precarização subjetiva: há uma culpabilização individualizada do profissional (assalariado ou não) pelo fracasso deste ideal de sucesso, como um profissional com obrigação de vencer à 'sua própria sorte' no mercado de trabalho;

3) a desvalorização da profissão, associada aos novos mecanismos de mercado como os convênios e clínicas 'populares', é percebida como um imperativo na busca por especialização, que representa um diferencial para ascensão profissional;

4) a construção de novas necessidades de consumo estético especializado por meio de esquemas de convencimento baseados em um saber-fazer profissional subsumido aos interesses de mercado é desvelada na relação dialógica profissional/paciente como um importante problema ético.

O quadro de crise paradigmática da profissão com ampliação das especialidades, especialmente pautadas no consumo estético, parece trazer a necessidade do debate da humanização e da ética para o campo da formação lato sensu em odontologia. Isso mostra a importância da regulamentação/normatização no ensino da ética e da bioética nos cursos de especialização, como previsto na resolução CFO n. 63/2005 sobre as normas para procedimentos nos conselhos de odontologia, destacando a importância da fiscalização de sua aplicação. No mesmo sentido, a formação permanente no 
trabalho do especialista exige participação proativa dos conselhos profissionais, entidades de classe e instituições governamentais/Estado relacionadas à saúde bucal.

O debate do papel social contemporâneo do profissional da odontologia, para além de uma odontologia de mercado e de uma ética puramente deontológica, aponta para a humanização e a bioética como centrais na construção da reflexividade. A construção de espaços coletivos de debate bioético, transversal e interdisciplinar deve abordar o impacto do consumo de novas tecnologias especializadas em saúde bucal na vida das pessoas. Nesse sentido, a estética associada à ética deve ser expressão de uma bucalidade reflexiva e válida como utopia de trabalho mais humano para os profissionais da odontologia.

\section{Colaboradores}

Doris Gomes trabalhou na concepção e redação do artigo. Flávia Regina Souza Ramos colaborou na revisão crítica.

Resumen Un nuevo tipo de relación entre la ciencia, la tecnología y la industria en la contemporaneidad estimula una fuerte expansión de realización del consumo de bienes y servicios especializados, con lo cual se crean diversos problemas éticos en este proceso. Este artículo tiene como objetivo analizar la relación entre la ética, la especialización y el mercado de trabajo en la odontología posreestructuración productiva. Se trata de una investigación cualitativa exploratoria y descriptiva, mediante la aplicación de un cuestionario en treinta estudiantes de un curso de especialización en el sur de Brasil. Las categorías se construyeron a través de los problemas éticos indicados en los discursos de los profesionales y analizadas por el método textual discursivo. Las categorías estudiadas fueron la búsqueda de la especialización como imperativo para diferenciarse en el mercado y los problemas éticos en la construcción de nuevas necesidades de consumo estético y especializado, basados en esquemas de convencimiento singulares profesional-paciente Un cuadro de crisis paradigmática de la profesión odontológica estimula la ampliación de las especialidades orientadas al consumo estético, lo que amplifica la importancia del debate ético en la formación lato sensu y también, en la formación permanente en el trabajo de salud bucal. Se indica la necesidad de la participación proactiva de los consejos profesionales, de asociaciones e instituciones gubernamentales relacionadas con la salud bucal en la construcción del debate ético y bioético, enfocado hacia el trabajo y la formación profesional.

Palabras clave ética; mercado laboral; especialización; salud bucal. 


\section{Notas}

1 Associação Educativa do Brasil, Matriz, Soebras, Brasil.

Doutora em Enfermagem pela Universidade Federal de Santa Catarina.

<dorisgomes@bol.com.br>

Correspondência: Rodovia Rafael da Rocha Pires, 3.913, Sambaqui, CEP 88051-001,

Florianópolis, Santa Catarina, Brasil.

2 Universidade Federal de Santa Catarina, Florianópolis, Santa Catarina, Brasil.

Doutora em Enfermagem pela Universidade Federal de Santa Catarina.

$<$ flaviar@ccs.ufsc.br>

3 Este artigo resultou da tese intitulada A subjetividade do profissional da saúde pós-reestruturação produtiva, de autoria de Doris Gomes, orientada por Flávia Regina Souza Ramos, apresentada ao Programa de Pós-Graduação em Enfermagem da Universidade Federal de Santa Catarina, em abril de 2013.

\section{Referências}

ALVES, Giovani. Trabalho e subjetividade: o espírito do toyotismo na era do capitalismo manipulatório. São Paulo: Boitempo, 2011.

AMORIM, Adriana G.; SOUZA, Elizabethe C. F. Problemas éticos vivenciados por dentistas: dialogando com a bioética para ampliar o olhar sobre o cotidiano da prática profissional. Ciência \& Saúde Coletiva, Rio de Janeiro, v. 15, n. 3, p. 869-878, 2010.

ARAÚJO, Rodolfo J. G.; MEDEIROS, Urubatan V. Análise das percepções de alunos de graduação sobre Odontologia do Trabalho. Revista Brasileira de Odontologia, Rio de Janeiro, v. 67, n. 2, p. 157-163, 2010.

BAUMAN, Zygmunt. Identidade: entrevista a Benedetto Vecchi. Rio de Janeiro: Zahar, 2005.

BECK, Ulrich. Sociedade de risco: rumo a uma outra modernidade. São Paulo: Editora $34,2010$.

BRASIL. Ministério da Educação. Resolução CNE/CES de 19 de fevereiro de 2002. Disponível em: <http://portal.mec.gov.br/
cne/arquivos/pdf/CES032002.pdf>. Acesso em: 20 set. 2013.

BRASIL. Ministério da Saúde. Departamento de Atenção Básica. Portal da Saúde. Centro de especialidades odontológicas. Brasília, [s.d.]. Disponível em: <http://dab.saude.gov.br/ portaldab/ape_brasil_sorridente.php? conteudo=ceo $>$. Acesso em: 7 jan. 2014.

CAPRARA, Andrea; LINS, Anamélia; FRANCO, Silva. Relação médico-paciente e humanização dos cuidados em saúde: limites, possibilidades, falácias. In: DESLANDES, Suely F. (Org.). Humanização dos cuidados em saúde: conceitos, dilemas e práticas. Rio de Janeiro: Editora Fiocruz, 2011, p. 85-108.

CECCIM, Ricardo B. et al. Imaginários sobre a perspectiva pública e privada do exercício profissional em saúde e a educação em saúde. In: PEREIRA, Rosemary C.; SILVESTRE, Rosa M. (Org.). Regulação e modelos assistenciais em saúde suplementar: produção científica da Rede de Centros Colaboradores da ANS - 2006/2008. Brasília: Organização Pan-Americana de Saúde, 2009, p. 199-233. 
CONSELHO FEDERAL DE ODONTOLOGIA (CFO). Consolidação das normas para procedimentos nos conselhos de odontologia aprovada pela resolução CFO 63/2005. Brasília, DF: CFO, 2005. Disponível em: <http://cfo. org.br/legislacao/normas-cfo-cros $>$. Acesso em: 20 set. 2013.

CORTINA, Adela. Ética mínima. São Paulo: Martins Fontes, 2009.

DEJOURS, Jacques C.; ABDOUCHELI, Elizabeth; JAYET, Christian. Psicodinâmica do trabalho: contribuições da escola dejouriana à análise da relação prazer, sofrimento e trabalho. São Paulo: Atlas, 2007.

DEJOURS, Jacques C. A loucura do trabalho: estudo de psicopatologia do trabalho. São Paulo: Cortez-Oboré, 1992.

FINKLER, Mireli; CAETANO, João C.; RAMOS, Flávia R. S. A dimensão ética da formação profissional em saúde: estudo de caso com cursos de graduação em odontologia. Ciência \& Saúde Coletiva, Rio de Janeiro, v. 16, n. 11, p. 4.481-4.492, 2011.

FOUCAULT, Michel. Microfísica do poder. Rio de Janeiro: Graal, 2000.

GIDDENS, Anthony. A vida em uma sociedade pós-tradicional. In: GIDDENS, Anthony; BACK, Ulrich; LACH, Scott. Modernização reflexiva: política, tradição e estética na ordem social moderna. São Paulo: Editora Unesp, 1997, p. 73-135.

GOMES, Doris; DA ROS, Marco A. A etiologia da cárie no estilo de pensamento da ciência odontológica. Ciência \& Saúde Coletiva, Rio de Janeiro, v. 13, n. 3, p. 1.081-1.090, 2008.

GRACIA, Diego. Pensar a bioética: metas e desafios. São Paulo: Loyola, 2010.

GUIMARÃES, Reinaldo. Desafios da pós-graduação em saúde humana no Brasil. Revista de Saúde Pública, São Paulo, v. 45, n. 1, p. 1-13, 2011.

HOBSBAWM, Eric. A era dos extremos. São Paulo: Companhia das Letras, 2002.
LACAZ, Francisco A. C.; SATO, Leny. Humanização e qualidade do processo de trabalho em saúde. In: DESLANDES, Suely F. (Org.). Humanização dos cuidados em saúde: conceitos, dilemas e práticas. Rio de Janeiro: Editora Fiocruz, 2011, p. 109-140.

MACHADO, Maria H. (Org.). Os médicos no Brasil: um retrato da realidade. Rio de Janeiro: Editora Fiocruz, 1997. Disponível em: <http://static.scielo.org/scielobooks/ bm9qp/pdf/machado-9788575412695.pdf $>$. Acesso em: 8 jan. 2015.

MÉSZÁROS, István. Para além do capital. São Paulo: Boitempo, 2002.

MORAES, Roque; GALIAZZI, Maria C. Análise textual discursiva. Rio Grande: Editora Unijuí, 2011.

NARVAI, Paulo C. Bases para uma saúde bucal de caráter coletivo. In: PINTO, Victor G. (Org.). Saúde bucal coletiva. São Paulo: Santos, 2013, p. 1-45 (Capítulo 1).

NARVAI, Paulo C. Saúde bucal coletiva: da odontologia sanitária à bucalidade. Revista de Saúde Pública, São Paulo, v. 40, n. esp., p. 141-147, 2006.

NUNES, Maria; LELES, Cláudio; GONÇALVES, Michele. Gênero e escolha por especialidades odontológicas: estudo com egressos de uma universidade pública federal. Revista Odontológica do Brasil Central, Goiânia, v. 19, n. 49 , p. 142-145, 2010.

OLIVEIRA, Rogério N.; MELANI, Rodolfo F. H.; SILVA, Ricardo H. A. Especialidades odontológicas: competências e legislação. In: SILVA, Ricardo H. A. e cols. Orientação profissional para o cirurgião-dentista: ética e legislação. São Paulo: Santos, 2011. p. 69-82.

PELBART, Peter P. Vida capital: ensaios de biopolítica. São Paulo: Iluminuras, 2003.

PIRES, Denise. Reestruturação produtiva e trabalho em saúde no Brasil. São Paulo: Annablume, 2008. 
SANTOS, Milton. Por uma outra globalização: do pensamento único à consciência universal. Rio de Janeiro: Record, 2011.

TSAKOS, Georgios; SHEIHAM, Aubrey. Avaliando necessidades através da abordagem sócio-odontológica. In: PINTO, Victor G. (Org.). Saúde bucal coletiva. São Paulo: Santos, 2013, p. 333-368 (Capítulo 6).

WERNECK, Marcos A. F.; FERREIRA, Renato $\mathrm{C}$. Tecnologia e saúde bucal: desafios da incorporação tecnológica. In: PINTO, Víctor G. (Org.). Saúde bucal coletiva. São Paulo: Santos, 2013, p. 401-413 (Capítulo 8).
ŽIŽEK, Slavoj. Em defesa das causas perdidas. São Paulo: Boitempo, 2011 la.

ŽIŽEK, Slavoj. Primeiro como tragédia, depois como farsa. São Paulo: Boitempo, 2011 b.

Recebido em 01/10/2012

Aprovado em 22/09/2014 